\title{
GENERALIZED HILBERT OPERATORS ON WEIGHTED MORREY-HERZ SPACES
}

\author{
KUANG JICHANG
}

Abstract. This paper give some necessary and sufficient conditions for the generalized Hilbert operators to be bounded on the weighted Morrey-Herz spaces. The corresponding new operator norm inequalities are obtained.

Mathematics subject classification (2010): 26D10, 47A30.

Keywords and phrases: Hilbert operator, Morrey-Herz spaces, norm inequality.

\section{REFERENCES}

[1] G. H. Hardy, J. E. Littlewood and G. Polya, Inequalities $\left(2^{r d}\right.$ ed), Cambridge University Press, London, 1952.

[2] E. F. Beckenbach and R. Bellman, Inequalities (2 $\left.{ }^{e d}\right)$, Springer-Verlag, New York, 1965.

[3] KuAng Jichang, Applied Inequalities ( $4^{r d}$ ed), Shangdong Science Press, Jinan, 2010. (in Chinese)

[4] Yang Bicheng, The norm of operator and Hilbert-type inequalities, Science Press, Beijing, 2009. (in Chinese)

[5] Ch. B. JR. Morrey, On the solutions of quasi-linear elliptic partial differential equations, Trans.Amer. Math.Soc. 43 (1938), 126-166.

[6] C. S. HERZ, Lipschitz spaces and Bernstein's theorem on absolutely convergent Fourier transforms, J. Math. Mech. 18 (1968/1969), 283-323.

[7] S. Z. LU AND L. F. XU, Boundedness of rough singular integral operators on the homogeneous Morrey-Herz spaces, Hokkaido Math. J. 34 (2005), 299-314.

[8] Kunng Jichang, Generalized Hilbert integral operators on the Herz spaces, Tamkang J.Math. 40, 2 (2009), 193-200.

[9] Kuang Jichang, Weighted Morrey-Herz spaces and applications, Applied Math.E-Notes 10 (2010), $159-166$.

[10] J. García-Cuerva AND J.-L. Rubio DE FrAnCIA, Weighted norm inequalities and related topics, North-Holland Publishing, Amsterdam, 1985.

[11] Bicheng Yang, Hilbert-type integral inequalities, Bentham Science Publishers Ltd, 2009. 